Int. J. Morphol.,

33(2):420-427, 2015.

\title{
Some Indicators of Fatness and Motor Fitness in Slovenian and Serbian Children
}

\author{
Algunos Indicadores de Obesidad y Aptitud Motriz en Niños Eslovenos y Serbios
}

\author{
${\text { Gregor Jurak*; Ivana Milanovic }{ }^{* *} \text {; Snezana Radisavljevic Janic }{ }^{* *} \text {; Maroje Soric }{ }^{* * *} \text { \& Marjeta Kovac }}^{*}$
}

JURAK, G.; MILANOVIC, I.; RADISAVLJEVIC, J. S.; SORIC, M. \& KOVAC, M. Some indicators of fatness and motor fitness in Slovenian and Serbian children. Int. J. Morphol., 33(2):420-427, 2015.

SUMMARY: The purpose of this study was to identify sex and age specific differences in fatness and motor fitness levels of children in two western Balkan countries in south-eastern Europe: Slovenia and Serbia. The sample consisted of 1,659 subjects of both sexes, aged from 9 to 15 years. Body height, body mass, triceps skinfold thickness, bent arm hang and standing long jump were used in the analysis. Ordinal regression was used to test differences in body mass index (BMI) categories among the countries. MANOVA was used to test the differences in motor fitness level. There were statistically significant $(\mathrm{p}<0.001)$ differences between the countries for the entire set of tested variables. Boys and girls from both countries had similar body height, body mass and BMI, yet Slovenians had smaller triceps skinfold thickness. Children from both countries were superior in standing long jump compared to their counterparts elsewhere in Europe. However, Slovenian boys and girls performed better than Serbian ones in both performed motor tests. Differences between countries in motor tests results were larger at age 9 than at age 14. Apparent trend was detected: with similar morphological characteristics, Slovenian children, especially girls, are physically fitter than Serbian ones. Sex is the only significant parameter $(p<0.001)$ of classifying into a BMI category. Boys have an approximate odds ratio of 1.75 for passing into a higher BMI category as girls. Among girls, the differences between countries were greater since the prevalence of overweight and obese girls in Slovenia decreases with age, while the reverse trend is observed in Serbia.

KEY WORDS: Obesity; Overweight; Body mass index; Physical fitness; Skinfold thickness.

\section{INTRODUCTION}

Nowadays many young people live in a half-virtual world of web social networks; they also choose to participate in physical activities less often than they used to (Brettschneider \& Naul, 2007). In connection with the sheltering praxis of parents (restriction of children from access to public spaces, e.g. playing on city playgrounds, from walking alone in their own neighbourhood, from crossing the street by themselves), individualisation (children's incorrect impressions of their role in society) and permissive education, sedentary lifestyles are common among young people in developed countries (Brettschneider \& Naul). According to the findings of secular trend studies, it can be concluded that changes in the lifestyles of young people in developed countries are manifesting themselves in an increased subcutaneous fatness (Olds et al., 2007), a higher proportion of the overweight population (Kovac et al., 2012; Wedderkopp et al., 2004) and deterioration of their cardiorespiratory and motor fitness (Tomkinson \& Olds, 2007; Tomkinson et al., 2007). Olds et al. (2007) found out that increases in fatness alone explain less than half the observed decline in aerobic fitness performance.

The geographic variability of fatness and fitness of children shows a north-south gradient in obesity levels (Wijnhoven et al., 2013) and the aerobic performance of European children (Tomkinson et al.). The superior fitness of northern and central European children has been noticed (Tomkinson et al.). Comparison studies among countries are interesting for researching factors that may affect the geographic variability of physical fitness of children. Most interpretations of fitness differentials focus on climate, genetic and embedded socio-cultural differences.

\footnotetext{
* Faculty of Sport, University of Ljubljana, Ljubljana, Slovenia.

** Faculty of Sport and Physical Education, University of Belgrade, Belgrade, Serbia.

${ }^{* * *}$ Faculty of Kinesiology, University of Zagreb, Zagreb, Croatia.
} 
There is just one recent study (Jurak et al., 2012) that compared the physical fitness test performance of young people from different countries of the former Yugoslavia, located in the western Balkans in south-eastern Europe. Little is therefore known about this matter since the disintegration of the federation. In some other countries that have also experienced significant social upheaval as a result of the collapse of communist regimes, research has been conducted on geographic variability, even secular trends (i.e. Baltic states; Jürimäe et al., 2007). In some countries of the former Yugoslavia (i.e. Slovenia and Croatia), there is a long tradition of monitoring morphology and physical fitness of children (in Slovenia data have been collected systematically on national representative samples since 1970 (Jurak et al., 2013); while in some other countries (i.e. Serbia, Macedonia, Bosnia and Herzegovina), such studies are performed occasionally (Ostojic et al., 2011). The former Yugoslavian countries have similar climate conditions, somewhat different socio-cultural backgrounds (Luthar \& Pusnik, 2010) and economic standards (IMF, 2010), similar school systems, similar models of sport, with a diverse range of options for out-of-school sports (especially sport clubs), and common genetic roots.

Therefore, the purpose of this study was to identify sex and age-specific differences in some indicators of fatness and motor fitness levels of children from two countries of the former Yugoslavia: Slovenia and Serbia.

\section{MATERIAL AND METHOD}

Subjects. The sample consisted of 1,659 subjects, 854 boys and 805 girls, aged from 9 to 15 years from 29 primary schools from the capitals of Serbia (Belgrade, population 1,273,000 inhabitants) and Slovenia (Ljubljana, population 259,000 inhabitants). In Belgrade because of organizational and finance limitation convenience sampling was used, while in Ljubljana sample was randomly selected. Only healthy children who regularly participated in physical education (PE) classes were tested. All children participated in $3 \times 45$ minutes of compulsory PE classes per week. Their out-ofschool physical activity was not registered. Having fully informed the children and their parents about the aims of the study, its protocol and the possible hazards and discomforts related to the procedures used, written consent was obtained from the parents of all participants. Also, the children gave their verbal assent and were free to withdraw from the study at any time. The study protocols were approved by the Ethics Committees of the Faculty of Sport of the University of Ljubljana and Faculty of Sport and Physical Education of the University of Belgrade.
Measurements. The data included three morphological and two motor tests (see Table I) using the SLOFIT protocols (Strel, 1997). In addition, the body mass index (BMI) was calculated as body weight in kilograms divided by body height in metres squared $\left(\mathrm{kg} / \mathrm{m}^{2}\right)$. Only two common motor tests were used, from among the different ranges of tests used in the different countries.

The qualified personnel conducted the testing sessions, with testing held in the morning (between 08:00 a.m. and 14:00 p.m.) in primary schools sport halls as part of compulsory PE classes. Subjects were measured in April and May, 2010. The testing sessions were structured so that following a brief $(\approx 10 \mathrm{~min})$ warm-up, the tasks were performed randomly. Subjects were weighed barefoot in their shorts and T-shirts to the nearest $0.1 \mathrm{~kg}$, with a medical balance scale; height was measured using a Martin metal anthropometer to the nearest $0.1 \mathrm{~cm}$, triceps skinfold thickness was measured with Holtain-Tanner callipers to the nearest $0.2 \mathrm{~mm}$. All instruments were calibrated each day at the beginning of measurements. All subjects were familiar with the testing equipment.

Upper-body muscular strength was assessed with the bent arm hang test. The child hangs from a bar with reverse grip for as long as possible, with the arms bent at 90 degrees. The chin had to be over the bar's plane. The time spent in this position, to the nearest second, was recorded. The maximum result of the test was 120 seconds. The test was performed once. A cylindrical horizontal bar and a stopwatch were used to perform the test. Lower body muscular strength was assessed with the standing long jump test. From a starting position immediately behind the line, standing with feet approximately at shoulder's width apart, the child jumped as far as possible with feet together. The result was recorded in centimetres. The test was performed twice, and the best performance was retained. A non-slip hard surface, chalk and a tape measure were used to perform the test.

Data entry and treatment. All hard copy data were manually entered into a spread sheet and checked for transcription errors, with corrections made where appropriate. The cut-off points of the International Obesity Task Force (Cole et al., 2000 ) for each 0.5 year were used to define BMI categories: normal, overweight and obese children. These criteria identify BMI values for each age associated with a predicted BMI of $25 \mathrm{~kg} / \mathrm{m}^{2}$ at 18 years for overweight and $30 \mathrm{~kg} / \mathrm{m}^{2}$ for obesity. A truncated age was used to present age categories of children, given in Table I (i.e. age of 11 was used for children aged 11.00-11.99 years). In further analyses about motor fitness levels, only children' data without missing test values were included in analyses. The data were complete for the remaining 1,461 children (88.1\%). 
Statistics. The basic parameters of the distribution of variables were calculated (mean, standard deviation). Data were tested for normality before analysis using histograms, normal probability plots and the Kolmogorov-Smirnov test. Multivariate analysis of variance (MANOVA) was used to test the differences in fatness and motor fitness level. The power of the concurrent influence on the entire set of dependent variables was assessed with Wilks' lambda; its statistical significance was tested with Bartlett's V transformation. The amount of explained variance of the entire system of dependent variables was estimated with an adjusted $R^{2}$ for the entire system of predictors, and with a partial $\mathrm{h}^{2}$ for individual predictors. Univariate tests were also carried out for each dependent variable separately: F-tests for the entire model, for its main effects and its interaction were applied. Ordinal regression with a logit link function was used to test differences in the BMI categories between countries. The data are reported as mean values unless otherwise stated. The level of statistical significance was set at $\mathrm{p}<0.05$. All analyses were performed using PASW Statistics 18 for Windows (SPSS Inc., Chicago, IL, USA).

Table I. Test means and standard deviations.

Body height (cm)

\begin{tabular}{|c|c|c|c|c|c|c|c|c|c|c|c|c|c|}
\hline & & \multicolumn{4}{|c|}{ Body height (cm) } & \multicolumn{4}{|c|}{ Body mass (kg) } & \multicolumn{4}{|c|}{ BMI $(\mathrm{kg} / \mathrm{m} 2)$} \\
\hline \multirow[b]{2}{*}{ Age } & & \multicolumn{2}{|c|}{$\begin{array}{c}\text { Slovenia } \\
n=864\end{array}$} & \multicolumn{2}{|c|}{$\begin{array}{l}\text { Serbia } \\
n=597 \\
\end{array}$} & \multicolumn{2}{|c|}{$\begin{array}{c}\text { Slovenia } \\
n=864\end{array}$} & \multicolumn{2}{|c|}{$\begin{array}{l}\text { Serbia } \\
n=\mathbf{5 9 7}\end{array}$} & \multicolumn{2}{|c|}{$\begin{array}{c}\text { Slovenia } \\
n=864\end{array}$} & \multicolumn{2}{|c|}{$\begin{array}{l}\text { Serbia } \\
n=597\end{array}$} \\
\hline & & Mean & SD & Mean & SD & Mean & SD & Mean & SD & Mean & SD & Mean & SD \\
\hline \multirow[t]{2}{*}{9 years } & $\mathrm{B}(\mathrm{n}=109)$ & 141.1 & 6.9 & 141.3 & 5.9 & 36.1 & 7.9 & 36.9 & 6.9 & 18.0 & 3.1 & 18.4 & 2.7 \\
\hline & $G(n=97)$ & 140.7 & 5.1 & 141.4 & 5.8 & 34.4 & 5.9 & 34.6 & 7.5 & 17.3 & 2.4 & 17.2 & 2.7 \\
\hline \multirow[t]{2}{*}{10 years } & $B(n=125)$ & 146.0 & 7.3 & 147.0 & 7.3 & 40.2 & 10.0 & 40.6 & 9.2 & 18.7 & 3.4 & 18.6 & 2.9 \\
\hline & $\mathrm{G}(\mathrm{n}=131)$ & 145.8 & 7.5 & 147.6 & 7.4 & 38.4 & 8.7 & 40.6 & 8.6 & 17.9 & 3.1 & 18.5 & 3.0 \\
\hline \multirow[t]{2}{*}{11 years } & $\mathrm{B}(\mathrm{n}=127)$ & 151.0 & 6.4 & 154.1 & 8.0 & 45.0 & 9.0 & 46.9 & 9.8 & 19.7 & 3.5 & 19.6 & 3.2 \\
\hline & $\mathrm{G}(\mathrm{n}=114)$ & 152.7 & 8.1 & 152.6 & 8.8 & 45.5 & 10.6 & 42.8 & 10.0 & 19.4 & 3.6 & 18.2 & 3.4 \\
\hline \multirow[t]{2}{*}{12 years } & $\mathrm{B}(\mathrm{n}=137)$ & 158.1 & 8.0 & 159.1 & 10.3 & 50.4 & 11.1 & 50.5 & 14.8 & 20.0 & 3.1 & 19.7 & 4.1 \\
\hline & $\mathrm{G}(\mathrm{n}=127)$ & 158.2 & 7.2 & 158.2 & 6.9 & 47.7 & 9.6 & 47.2 & 8.3 & 18.9 & 3.1 & 18.8 & 2.8 \\
\hline \multirow[t]{2}{*}{13 years } & $\mathrm{B}(\mathrm{n}=127)$ & 165.3 & 9.4 & 166.3 & 9.8 & 56.3 & 12.7 & 56.2 & 12.6 & 20.5 & 3.7 & 20.2 & 3.5 \\
\hline & $\mathrm{G}(\mathrm{n}=126)$ & 163.5 & 7.1 & 163.9 & 5.8 & 54.3 & 10.3 & 54.0 & 8.5 & 20.2 & 3.2 & 20.1 & 3.0 \\
\hline \multirow[t]{5}{*}{14 years } & $\mathrm{B}(\mathrm{n}=135)$ & 172.8 & 7.7 & 172.6 & 7.7 & 64.6 & 12.2 & 63.3 & 14.7 & 21.6 & 3.3 & 21.1 & 3.8 \\
\hline & $\mathrm{G}(\mathrm{n}=106)$ & 165.4 & 5.5 & 164.6 & 5.3 & 56.0 & 8.3 & 56.7 & 8.9 & 20.5 & 2.8 & 20.9 & 2.8 \\
\hline & & \multicolumn{4}{|c|}{ Triceps skinfold (mm) } & \multicolumn{4}{|c|}{ Bent arm hang (s) } & \multicolumn{4}{|c|}{ Standing long jump (cm) } \\
\hline & & \multicolumn{2}{|c|}{$\begin{array}{c}\text { Slovenia } \\
n=864\end{array}$} & \multicolumn{2}{|c|}{$\begin{array}{l}\text { Serbia } \\
n=597\end{array}$} & \multicolumn{2}{|c|}{$\begin{array}{c}\text { Slovenia } \\
n=864\end{array}$} & \multicolumn{2}{|c|}{$\begin{array}{l}\text { Serbia } \\
n=597\end{array}$} & \multicolumn{2}{|c|}{$\begin{array}{c}\text { Slovenia } \\
n=864\end{array}$} & \multicolumn{2}{|c|}{$\begin{array}{l}\text { Serbia } \\
n=597\end{array}$} \\
\hline & & Mean & SD & Mean & SD & Mean & SD & Mean & SD & Mean & SD & Mean & SD \\
\hline \multirow[t]{2}{*}{9 years } & $\mathrm{B}(\mathrm{n}=109)$ & 12.7 & 5.1 & 14.1 & 4.9 & 39.2 & 28.3 & 13.9 & 9.8 & 154.4 & 24.4 & 128.0 & 18.5 \\
\hline & $G(n=97)$ & 13.2 & 3.9 & 14.5 & 4.9 & 33.0 & 21.7 & 14.0 & 8.2 & 146.3 & 15.8 & 115.7 & 17.8 \\
\hline \multirow[t]{2}{*}{10 years } & $B(n=125)$ & 12.8 & 5.5 & 14.4 & 4.7 & 38.0 & 32.1 & 15.3 & 11.0 & 158.6 & 22.8 & 134.6 & 21.3 \\
\hline & $\mathrm{G}(\mathrm{n}=131)$ & 14.1 & 6.0 & 15.9 & 4.6 & 29.9 & 23.4 & 13.0 & 7.4 & 150.5 & 19.4 & 126.9 & 19.0 \\
\hline \multirow[t]{2}{*}{11 years } & $\mathrm{B}(\mathrm{n}=127)$ & 14.9 & 5.9 & 13.6 & 4.9 & 29.1 & 22.9 & 25.3 & 16.8 & 164.5 & 19.6 & 157.3 & 18.9 \\
\hline & $\mathrm{G}(\mathrm{n}=114)$ & 14.2 & 6.0 & 15.3 & 5.5 & 33.2 & 26.8 & 15.3 & 11.3 & 161.1 & 21.0 & 138.3 & 17.8 \\
\hline 12 years & $\mathrm{B}(\mathrm{n}=137)$ & 13.4 & 5.9 & 13.6 & 6.3 & 31.4 & 26.5 & 24.5 & 11.8 & 171.1 & 24.8 & 164.9 & 21.8 \\
\hline & $\mathrm{G}(\mathrm{n}=127)$ & 13.2 & 4.9 & 14.3 & 4.6 & 33.3 & 24.9 & 24.2 & 16.2 & 166.0 & 20.0 & 143.9 & 20.0 \\
\hline 13 years & $\mathrm{B}(\mathrm{n}=127)$ & 13.0 & 6.0 & 13.1 & 6.3 & 37.6 & 29.4 & 39.5 & 23.1 & 186.3 & 25.1 & 177.8 & 24.1 \\
\hline & $\mathrm{G}(\mathrm{n}=126)$ & 13.2 & 4.9 & 15.8 & 4.6 & 31.9 & 23.8 & 25.4 & 15.9 & 169.1 & 26.0 & 147.9 & 19.3 \\
\hline 14 years & $\mathrm{B}(\mathrm{n}=135)$ & 12.1 & 5.9 & 12.7 & 6.0 & 45.2 & 26.6 & 42.0 & 26.0 & 204.7 & 31.0 & 190.5 & 24.8 \\
\hline & $\mathrm{G}(\mathrm{n}=106)$ & 13.9 & 4.7 & 17.5 & 4.8 & 36.9 & 23.6 & 28.4 & 18.1 & 175.7 & 21.1 & 154.0 & 19.8 \\
\hline
\end{tabular}

$\mathrm{B}=$ Boys, $\mathrm{G}=$ Girls

\section{RESULTS}

Boys and girls from Slovenia and Serbia have similar body height, body mass and BMI, yet Slovenians have smaller triceps skinfold thickness, especially girls at age 13 and 14 years (Table I). Slovenian boys and girls performed better than Serbian ones in both motor tests. Particularly large differences are obtained in girls. Differences between countries in motor tests results are larger at age 9 than at age 14 .

All the differences between the subjects are statistically significant for the entire set of morphological and motor variables (see Table II for multivariate statistic). As expected, the biggest proportion of variance $(21.0 \%)$ is explained by age group. Furthermore, the influence of country (19.6\% of explained variance) and sex (18.1\%) are quite large, whereas two-way interactions are smaller. The highest is the interaction of sex and age group (2.2\%). The three-way country-sex-age group interaction is negligible. 


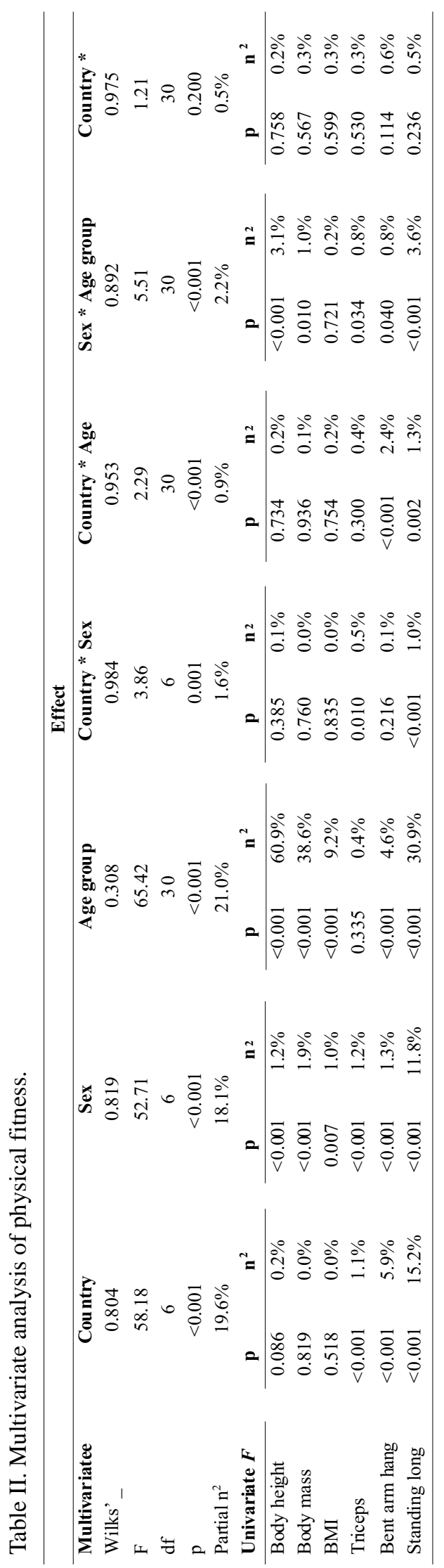

The univariate tests for the main factors and interactions show the considerable effect on all the dependent variables $(\mathrm{p}<0.001)$, particularly body height (adj. $\left.\mathrm{R}^{2}=63.6 \%\right)$, standing long jump (adj. $\mathrm{R}^{2}=46.7 \%$ ) and body mass (adj. $\mathrm{R}^{2}=42.0 \%$ ). These tests also show the most significant impact of age group (see Table III for univariate statistic). The proportion of explained variance for other variables is: $14.0 \%$ for bent arm hang, $11.2 \%$ for BMI and $4.1 \%$ for triceps skinfold thickness.

Differences between the countries are negligible for body height, body mass and BMI and considerable for triceps skinfold thickness and both motor variables (see Table II for univariate statistic). The largest difference observed is for standing long jump. Sex has much less influence, as it reaches $11.8 \%$ of the explained variance in the test standing long jump, but only a small variance in other tests. Differences between the age groups are considerable in all tests but triceps skinfold thickness.

The univariate interaction is relatively small between the main effects (see the rightmost columns of Table II for univariate statistic) as it reaches a maximum $3.6 \%$ of the explained variance (standing long jump in interaction of sex and age group).

Predicting the frequency of BMI category with respect to sex, country and age group was analyzed with ordinal regression. Model fitting with -2LL method is highly statistically significant $(\mathrm{p}<0.001)$, yet the effect of chosen variables is small, since pseudo $R^{2}$ measures are low $(\mathrm{Cox}$ and Snell $=0.016$, Nagelkerke $=0.023$, McFadden $=$ $0.013)$. Sex is the only statistically significant parameter $(\mathrm{p}<0.001)$; boys have an approximate odds ratio of 1.75 for passing into a higher BMI group compared with girls.

Distribution of BMI categories according to age-specific values of BMI display differences between the countries, sex and age groups (Table I). Based on the regression analysis results, sex proved to be a more significant factor than nationality in the observed BMI groups. It can be seen that in both countries there is a greater proportion of overweight and obese boys than girls. Differences between sexes in separate age groups are bigger in Slovenia because of reverse trend in older age groups, where the percentage of overweight and obese girls has decreased and in boys has increased.

The proportion of overweight and obese children in separate age groups in both countries is more similar in boys. At the age of 9 , in both countries there is $25 \%$ prevalence of overweight and obese boys; at the age of 14 that prevalence increases to approximately $30 \%$. In girls, there are bigger differences among countries. The proportion of Slovenian 9-year-old overweight and obese girls is bigger (18.2\%) than of Serbian ones (12.0\%). The situation with 14-years-old girls is reverse: in Slovenia $10.4 \%$ of girls are overweight and obese, while in it is Serbia $20.0 \%$. However, these differences were not significant in our multivariate analysis. 
JURAK, G.; MILANOVIC, I.; RADISAVLJEVIC, J. S.; SORIC, M. \& KOVAC, M. Some indicators of fatness and motor fitness in Slovenian and Serbian children. Int. J. Morphol., 33(2):420-427, 2015.

Table III. Prevalence of normal, overweight and obese children.

\begin{tabular}{|c|c|c|c|c|c|c|c|c|c|c|c|c|}
\hline \multirow[b]{3}{*}{ Age } & \multicolumn{6}{|c|}{ Slovenia $(n=884)$} & \multicolumn{6}{|c|}{ Serbia $(n=775)$} \\
\hline & \multicolumn{3}{|c|}{ Boys } & \multicolumn{3}{|c|}{ Girls } & \multicolumn{3}{|c|}{ Boys } & \multicolumn{3}{|c|}{ Girls } \\
\hline & $\mathbf{N}$ & OW & OB & $\mathbf{N}$ & OW & OB & $\mathbf{N}$ & OW & OB & $\mathbf{N}$ & OW & OB \\
\hline 9 years $(n=226)$ & 74.5 & 17.6 & 7.8 & 81.8 & 18.2 & 0.0 & 75.4 & 21.7 & 2.9 & 86.3 & 11.8 & 2.0 \\
\hline 10 years $(n=283)$ & 72.7 & 22.1 & 5.2 & 79.7 & 17.7 & 2.5 & 81.7 & 13.3 & 5.0 & 83.6 & 14.9 & 1.5 \\
\hline 11 years $(n=278)$ & 70.1 & 24.7 & 5.2 & 73.2 & 19.7 & 7.0 & 71.4 & 24.3 & 4.3 & 85.0 & 11.7 & 3.3 \\
\hline 12 years $(n=301)$ & 77.4 & 20.2 & 2.4 & 86.1 & 11.4 & 2.5 & 77.6 & 14.9 & 7.5 & 84.5 & 12.7 & 2.8 \\
\hline 13 years $(n=290)$ & 71.4 & 23.4 & 5.2 & 83.1 & 13.0 & 3.9 & 77.9 & 20.6 & 1.5 & 86.8 & 10.3 & 2.9 \\
\hline 14 years $(n=281)$ & 70.0 & 25.0 & 5.0 & 89.6 & 9.1 & 1.3 & 71.6 & 23.0 & 5.4 & 80.0 & 18.0 & 2.0 \\
\hline
\end{tabular}

$\mathrm{N}=$ Normal weight, $\mathrm{OW}=$ Overweight, $\mathrm{OB}=$ Obese.

\section{DISCUSSION}

With this study, we were able to show the differences in some characteristics of fatness and some aspects of motor fitness of children from Slovenia and Serbia. The main finding is that Serbian children showed poorer motor fitness despite similar body build as Slovenian children, yet children from both countries performed better in selected motor tests then their counterparts from elsewhere in Europe.

Little is known about the geographic variability in children's physical fitness performances and the reasons that determine the differences. Countries of the former Yugoslavia are located in central and south-eastern Europe. Lower prevalence of overweight and obesity and superior physical fitness performance of Slovenian and Serbian children would therefore be expected according to previously found gradient of prevalence of overweight and obesity in Europe (Wijnhoven et al.) and fitness performance levels (Tomkinson et al.).

A comparison of the prevalence of overweight and obesity in our study with some recent studies on national samples (Wijnhoven et al.) shows lower prevalence in Slovenian and Serbian girls than their counterparts across Europe, yet boys are placed near to their counterparts from western and southern Europe. Our key finding about differences in the prevalence of overweight and obesity among Slovenian and Serbian children is that sex is a more significant classifying predictor in BMI group than nationality. The prevalence of overweight and obesity is much higher in boys. This was found also in the majority of European countries (Wijnhoven et al.), also in Slovenia (Kovac et al.) while for Serbian children previous findings are controversial (Ostojic et al.; Radisavljevic Janic et al., 2013).

Several studies indicate that obese and overweight children had the greatest risk of becoming obese or overweight young adults (Starc \& Strel, 2011). Tracking obesity through childhood is therefore an important issue. Our study was not made on a cohort, so we did not track how children move within BMI groups with aging; however, some trends can be observed when we compare the percentage of children in BMI groups of different ages in Table I, although our model of analyse was not designed for this purpose. In boys, the trend is similar in both countries. With age, there are more overweight and obese boys. The same trend has been observed in other cross-sectional (Kovac et al.) and cohort studies (Starc \& Strel). In girls, an opposite trend has been found. In Slovenia, the percentage of overweight and obese girls is decreasing with age, while among Serbian girls it is increasing. A positive trend of prevalence of overweight and obesity in Slovenian girls has also been observed by Starc \& Strel. The same trend in this age period has been observed in some European countries (Jebb et al., 2004), while in other (Karayiannis et al., 2003) negative trends of the prevalence of overweight and obesity of girls with aging has been observed. Results of another recent study in Serbia (Ostojic et al.) don't reveal age differences.

A comparison of our results with a recent HELENA study (Ortega et al., 2011) indicates that fitness performance in lower-limb explosive strength (standing long jump) of Serbian boys and girls is in the $70^{\text {th }}$ percentile of tests performance values of their counterparts from Europe, while Slovenian children performed even better. Slovenian boys are in the $80^{\text {th }}$ percentile and Slovenian girls are in the $85^{\text {th }}$ percentile. Such good results have been observed in previous smaller study on Slovenian and Serbian 12-years olds (Jurak et al., 2012) and on other studies on Slovenian samples (Strel et al., 2007). Results from the bent arm hang test are not comparable with those from the HELENA study since they were using Eurofit protocol in this test, where there is a different placement of the palms (forward grip), which is harder to perform. A comparison with results from international studies from about ten years ago (Telama et al.) indicate that children from Slovenia and Serbia have motor fitness performance on the level that their peers in some other European countries used to have a decade ago. 
By presenting the comparison between motor fitness among Slovenian and Serbian children, it is possible to detect, that with similar morphological characteristics, Slovenian children, especially girls, are physically fitter than Serbian ones. The differences between children motor fitness among countries can hardly be explained with the tested morphological characteristics since no significant differences in body height, body mass and BMI were noted. This is not so unusual since the data about the influence of those characteristics on the performance of motor tests are contradictory. Body mass was found to be negatively connected with body movement (especially running capacity) in several studies (Strel et al.; Tomkinson \& Olds; Wedderkopp et al.), yet the data about the influence of body height on motor tests performance are contradictory (Mota et al., 2002). However, it should be emphasised that while the average BMI values in both countries are similar, triceps skinfold thickness was considerably higher in Serbian children compared with their Slovenian peers. This could indicate that the two groups of children differ regarding body composition with Slovenian children having more lean mass and less body fat compared with their peers in Serbia. However, this assumption should be tested with a more accurate method for assessing body composition.

Some other factors, could have also contributed to the differences in motor fitness among Slovenian and Serbian children. Olds et al. (2006) found a relationship between climate and children fitness performance but Slovenia and Serbia have similar climates. Furthermore, they have same genetic roots (Slavic); therefore, it seems likely that sociocultural factors are important. Findings from Tomkinson et al. indicate that scheduled minutes of school PE are unrelated to fitness performance of children. Both Slovenia and Serbia have a common basis for PE curriculum, and both have 135 minutes of PE per week in the observed school period. However, Slovenia has one important differential characteristic: from age 11 onward, PE classes are usually being led separately for girls and boys in groups up to 20 students by a PE teacher. Girls are being mostly instructed by a female PE teacher. In smaller and more homogeneous groups, Slovenian girls could be more encouraged to develop their motor skills and physical fitness performances. Girls enter adolescence earlier, which influences their interest in physical fitness. In such a learning environment, they could comprehend $\mathrm{PE}$ in more health-related manner. This could explain the considerable decrease of overweight and obese Slovenian girls with age.

Limitations. There are limitations to our study and care should be taken in generalization, since the study was not performed on national representative samples, had limited number of morphological and motor variables and did not control for many important environmental and social factors influencing the physical and motor development of children. We are aware that the differences between children motor fitness between countries could be result of different maturation level of children, but we were not able to determine the biological age of children from our data. Another uncontrolled factor could be conditions for PE in schools. In Slovenia there is a wide selection of extra-curricular sports activities for younger ages (up to 10 years) and better learning conditions: larger sport areas per students and better equipment in sport halls. We were also unable to gather the information on out-of-school physical activity of children. Slovenian 11-year-olds are in the top three within 35 European countries in physical activity (Roberts et al., 2004). Consequently, more frequent physical activity of Slovenian children could be expected. Also, we gathered no information on other social factors that could influence on physical activity. Slovenians have almost three times greater purchasing power than the Serbians (IMF). Overall wealth of the country could be an important factor, which ensures resources in schools and in the broader community in order to engage children in active lifestyles. Slovenia has a GDP per capita level of USD 24,417 while Serbia's is USD 5,809 (IMF). However, wealthy countries may offer more opportunities for sedentary pastimes and passive lifestyles. Therefore, no firm relationship between children's physical performance and gross indicators of economic status was found (Tomkinson et al.).

\section{CONCLUSIONS}

This study gains knowledge about the level and variability of the fatness and motor fitness of children in the western Balkan region in south-east Europe. Prevalence of overweight and obesity of Slovenian and Serbian children compared to their counterparts across Europe vary by sex. While girls show one of the lowest prevalence in Europe, boys are placed near to their counterparts from western and southern Europe. As regards the motor fitness, children from both countries performed better in selected motor tests than their counterparts from elswere in Europe, especially girls were dominant. Hovewer, studied variables cannot explain somewhat better motor fitness of Slovenian then Serbian children. Further investigations should include more morphological and motor variables. In addition, they should focus on some of the factors of socio-cultural environment, such as standards in PE teaching (number of students per teacher, access to sports halls with quality sports equipment), competences in PE teaching (PE teachers and class teachers), the extracurricular sport activity of young people and environmental conditions (availability and access to sports facilities), which could explain differences in of fatness and motor fitness. 


\section{ACKNOWLEDGEMENTS}

This paper is part of the project Bio-psycho-social contexts of kinesiology No. P5-0587-142 (2009-2012) that was funded by Slovenian Research Agency and the project The effects of physical activity application to locomotor, metabolic, psychosocial and educational status with population of the Republic of Serbia No. III47015 (20112014) financially supported by the Ministry of Education and Science of the Republic of Serbia.

JURAK, G.; MILANOVIC, I.; RADISAVLJEVIC, J. S.; SORIC, M. \& KOVAC, M. Algunos indicadores de la obesidad y la aptitud motriz en niños eslovenos y serbios. Int. J. Morphol., 33(2):420-427, 2015.

RESUMEN: El propósito de este estudio fue identificar las diferencias específicas de sexo y edad en la aptitud y niveles de condición física en niños de dos países de los Balcanes occidentales en el sudeste de Europa: Eslovenia y Serbia. La muestra consistió en 1.659 sujetos de ambos sexos, con edades entre los 9 y 15 años. Para el análisis se utilizaron la altura corporal, masa corporal, espesor del pliegue cutáneo del tríceps, brazo doblado al colgar y de pie en salto largo. Se utilizó la regresión ordinal para probar las diferencias en el índice de masa corporal (IMC) categorías entre los países. El análisis MANOVA fue utilizado para probar las diferencias en el nivel de condición motriz física. El conjunto de variables analizadas $(\mathrm{p}<0,001)$ entre los países no fueron estadísticamente significativas. Los niños y niñas de ambos países tenían similar altura y masa corporal e IMC, pero en los eslovenos los pliegues cutáneos del triceps más pequeños. Los niños de ambos países fueron superiores en salto largo en comparación con sus homólogos de otras partes de Europa. Sin embargo, los niños y las niñas eslovenos obtuvieron mejores resultados que los serbios en ambas pruebas de motricidad. Las diferencias en los resultados de las pruebas de motricidad entre los países fueron mayores a los 9 años de edad, a los 14 años se detectó una tendencia aparente: con características morfológicas similares, los niños eslovenos, particularmente las niñas, se encontraban en mejores condiciones físicas que los niños serbios. El sexo es el único parámetro significativo $(\mathrm{p}<0,001)$ de clasificar en una categoría de IMC. Los niños tienen una probabilidad promedio aproximada de 1,75 para pasar a una categoría superior IMC tal como las niñas. Entre las niñas, las diferencias entre los países eran mayores, ya que la prevalencia de las niñas con sobrepeso y obesidad en Eslovenia disminuyen con la edad, mientras que se observó una tendencia inversa en Serbia.

PALABRAS ClAVE: Obesidad; Sobrepeso; Índice de Masa Corporal; Condición física; Grosor del pliege cutaneo.

\section{REFERENCES}

Brettschneider, W. D. \& Naul, R. Obesity in Europe. Young peoples physical activity and sedentary lifestyles. Frankfurt, Peter Lang, 2007.

Cole, T. J.; Bellizzi, M. C.; Flegal, K. M. \& Dietz, W. H. Establishing a standard definition for child overweight and obesity worldwide: international survey. BMJ., 320(7244):1240-3, 2000 .

International Monetary Fund (IMF). World Economic Outlook Database, April 2010. Washington D. C., International Monetary Fund (IMF), 2010.

Jebb, S. A.; Rennie, K. L. \& Cole, T. J. Prevalence of overweight and obesity among young people in Great Britain. Public Health Nutr., 7(3):461-5, 2004.

Jurak, G.; Kovac, M. \& Starc, G. The ACDSi 2013 -- The Analysis of Children's Development in Slovenia 2013: Study protocol. Anthropol. Noteb., 19(3):123-43, 2013.

Jurak, G.; Radisavljevic Janic, S.; Milanovic, S.; Strel, J. \& Kovac, M. Physical fitness of 12-year-old girls from capitals of Serbia and Slovenia. Kinanthropologica, 48(1):42-50, 2012.
Jürimäe, T.; Volbekiene, V.; Jürimäe, J. \& Tomkinson, G. R. Changes in Eurofit test performance of Estonian and Lithuanian children and adolescents (1992-2002). Med. Sport Sci., 50:12942, 2007.

Karayiannis, D.; Yannakoulia, M.; Terzidou, M.; Sidossis, L. S. \& Kokkevi, A. Prevalence of overweight and obesity in Greek school-aged children and adolescents. Eur. J. Clin. Nutr., 57(9):1189-92, 2003.

Kovac, M.; Jurak, G. \& Leskosek, B. The prevalence of excess weight and obesity in Slovenian children and adolescents from 1991 to 2011. Anthropol. Noteb., 18(1):91-103, 2012.

Luthar, B. \& Pusnik, M. Remembering Utopia: The Culture of Everyday Life in Socialist Yugoslavia. Washington D. C., New Academia Publishing, 2010.

Mota, J.; Guerra, S.; Leandro, C.; Pinto, A.; Ribeiro, J. C. \& Duarte, J. A. Association of maturation, sex, and body fat in cardiorespiratory fitness. Am. J. Hum. Biol., 14(6):707-12, 2002.

Olds, T.; Tomkinson, G.; Léger, L. \& Cazorla, G. Worldwide variation in the performance of children and adolescents: an 
analysis of 109 studies of the 20 -m shuttle run test in 37 countries. J. Sports Sci., 24(10):1025-38, 2006.

Olds, T. S.; Ridley, K. \& Tomkinson, G. R. Declines in aerobic fitness: are they only due to increasing fatness? Med. Sport Sci., 50:226-40, 2007.

Ortega, F. B.; Artero, E. G.; Ruiz, J. R.; España-Romero, V.; Jiménez-Pavón, D.; Vicente-Rodriguez, G.; Moreno, L. A.; Manios, Y.; Béghin, L.; Ottevaere, C.; Ciarapica, D.; Sarri, K.; Dietrich, S.; Blair, S. N.; Kersting, M.; Molnar, D.; González-Gross, M.; Gutiérrez, A.; Sjöström, M.; Castillo, M. J. \& HELENA study. Physical fitness levels among European adolescents: the HELENA study. Br. J. Sports Med., 45(1):209, 2011.

Ostojic, S. M.; Stojanovic, M. D.; Stojanovic, V.; Maric, J. \& Njaradi, N. Correlation between fitness and fatness in 6-14year old Serbian school children. J. Health Popul. Nutr., 29(1):53-60, 2011.

Radisavljevic Janic, S.; Milanovic, I.; Zivkovic, M. \& Mirkov, D. Prevalence of overweight and obesity among Belgrade youth: A study in a representative sample of 9-14-year-old children and adolescents. Anthropol. Noteb., 19(3):71-80, 2013.

Roberts, C.; Tynjala, J. \& Komkov, A. Physical activity. In: Currie, C.; Roberts, C.; Morgan, A.; Smith, R.; Settertobulte, W. \& Samdal, O. (Eds.). Young people's health in context: Health behaviour in school-aged children (HBSC) study: International report from the 2001/2002 survey. Copenhagen, World Health Organization, 2004. pp.90-7.

Starc, G. \& Strel, J. Tracking excess weight and obesity from childhood to young adulthood: a 12-year prospective cohort study in Slovenia. Public Health Nutr., 14(1):49-55, 2011.

Strel, J. Sports educational chart. Ljubljana, Ministry of Education and Sport, 1997.

Strel, J.; Kovac, M. \& Jurak, G. Physical and motor development, sport activities and lifestyles of Slovenian children and youth - changes in the last few decades. In: Brettschneider, W. D. \& Naul, R. (Eds.). Obesity in Europe: young people's physical activity and sedentary lifestyles. Frankfurt, Peter Lang, 2007. pp.243-64.

Telama, R.; Naul, R.; Nupponen, H.; Rychteck $\neq$, A. \& Vuolle, P. Physical fitness, sporting lifestyles, and Olympic ideals: crosscultural studies on youth sport in Europe. Schorndorf, Verlag Hofmann, 2002.

Tomkinson, G. R. \& Olds, T. S. Secular changes in pediatric aerobic fitness test performance: the global picture. Med. Sport Sci., 50:46-66, 2007.

Tomkinson, G. R.; Olds, T. S. \& Borms, J. Who are the Eurofittest? Med. Sport Sci., 50:104-28, 2007.
Wedderkopp, N.; Froberg, K.; Hansen, H. S. \& Andersen, L. B. Secular trends in physical fitness and obesity in Danish 9-yearold girls and boys: Odense School Child Study and Danish substudy of the European Youth Heart Study. Scand. J. Med. Sci. Sports, 14(3):150-5, 2004.

Wijnhoven, T. M.; van Raaij, J. M.; Spinelli, A.; Rito, A. I.; Hovengen, R.; Kunesova, M.; Starc, G.; Rutter, H.; Sjöberg, A.; Petrauskiene, A.; O'Dwyer, U.; Petrova, S.; Farrugia Sant'angelo, V.; Wauters, M.; Yngve, A.; Rubana, I. M. \& Breda, J. WHO European Childhood Obesity Surveillance Initiative 2008: weight, height and body mass index in 6-9year-old children. Pediatr. Obes., 8(2):79-97, 2013.

\section{Correspondence to: \\ Gregor Jurak \\ Faculty of Sport \\ University of Ljubljana \\ Gortanova 22, 1000 \\ Ljubljana \\ SLOVENIA}

Email: gregor.jurak@fsp.uni-lj.si

Received: 04-10-2014

Accepted: 30-01-2015 